\title{
Sulindac Sulfide Differentially Induces Apoptosis in Smac- Proficient and -Deficient Human Colon Cancer Cells
}

\author{
Jingxue Shi*, Qin He*, Jie An, Hong Sun, Ying Huang and M. Saeed Sheikh \\ Department of Pharmacology, State University of New York, Upstate Medical University, \\ Syracuse, New York
}

*These authors contributed equally to this work.

\begin{abstract}
Sulindac, the non-steroidal anti-inflammatory drug has shown promise in the prevention of colon cancer but the molecular mechanisms by which it mediates such effects remain to be elucidated. Sulindac sulfide is the major active metabolite of sulindac and believed to be responsible for mediating the effects of sulindac. Previously, our group and others have shown that sulindac sulfide induces apoptosis by engaging death receptor and mitochondrial pathways and that a cross-talk exists between these two pathways during sulindac sulfide-induced apoptosis. Second mitochondrial-derived activator (Smac) is an important pro-apoptotic molecule that activates caspases by antagonizing the inhibitors of apoptosis (IAPs). In this study, we have utilized Smac-proficient and -deficient human colon cancer cells to investigate the role of Smac during sulindac sulfide-induced apoptosis and found that Smac deficiency affects sulindac sulfide-induced apoptosis in human colon cancer cells. Sulindac sulfide-induced apoptosis is coupled with upregulation of death receptor 5 (DR5), and activation of caspases 3,9 and 8 in Smacproficient cells. In Smac-deficient cells, although sulindac sulfide-induced DR5 upregulation is not altered, activation of caspases 3,9 and 8 is affected. Smac deficiency also abrogates sulindac sulfide-induced cytochrome c release from mitochondria into cytosol. Our results, therefore, demonstrate that Smac is involved in sulindac sulfide-induced apoptotic signal transduction in human colon cancer cells and highlight the existence of a potential cross-talk between Smac and cytochrome $\mathrm{c}$.
\end{abstract}

Received 05/22/09; accepted 05/24/09

Correspondence: M. Saeed Sheikh, M.D., Ph.D., Department of Pharmacology, SUNY Upstate Medical University, 750 E. Adams St. Syracuse, NY 13210, USA. Tel. 315-464-8015, Fax. 315-464-8014. email: sheikhm@upstate.edu
Keywords: NSAIDs; Sulindac sulfide; Death receptor 5; Smac; Colon cancer

\section{Introduction}

Nonsteroidal anti-inflammatory drugs (NSAIDs) are common drugs frequently used for headaches, fevers and pains. NSAIDs mediate their effects by inhibiting two cyclooxygenase (COX) enzymes including COX-1 and COX-2 (reviewed in 1, 2). COX1 is constitutively expressed whereas COX-2 is an inducible enzyme and additional agents have been developed to selectively inhibit COX-2 (reviewed in 1, 2). Aside from their analgesic, antipyretic and antiinflammatory effects, NSAIDs have shown promise as anticancer agents. For example, a large body of epidemiological evidence suggests that the long-term use of aspirin or other NSAIDs leads to a lower risk of colorectal adenomatous polyps and colon cancer (3-6). Although COX-2 selective inhibitors have also shown anticancer potential, recent clinical trials have also reported their adverse cardiovascular effects due to long-term use (7). The molecular mechanisms by which these agents mediate their anticancer or cardiovascular effects remain to be fully elucidated.

Sulindac is an NSAID that has also shown significant anticancer potential in rodents $(8,9)$. The role of sulindac in causing regression of polyps in Familial Adenomatous Polyposis (FAP) patients is also well established (10, 11). FAP is a hereditary disorder and the affected individuals develop a large number of colonic polyps predisposing them to colon cancer (10, 11 and references therein). Although sulindac has shown promise in causing regression of polyps, drug resistance eventually develops making this drug less effective $(12,13)$. Further studies are therefore, needed to better understand the molecular mechanism by which sulindac mediates its anticancer effects, as the outcome of such studies 
will likely improve its use in the clinic and facilitate the development of newer and less toxic agents.

Sulindac is a prodrug that is metabolized in vivo and sulindac sulfide is the major active metabolite of sulindac (14). Sulindac sulfide has been shown to induce apoptosis in a variety of cancer cell lines representing various malignancies including colon cancer (14-16). Previously, we and others have shown that sulindac sulfide induces apoptosis by engaging death receptor and mitochondrial pathways $(17,18)$. In our previous studies, we reported that sulindac sulfide induced apoptosis by engaging the death receptor (DR5)dependent apoptotic pathway (17). Sulindac sulfide upregulated DR5 expression at both mRNA and protein levels in multiple colon and prostate cancer cell lines and activated caspase 8 (17). We also reported cooperativity between Apo2L/TRAIL, the ligand for DR5, and sulindac sulfide to induce apoptosis $(17,19)$.

In addition to engaging the death receptor pathway, sulindac sulfide has also been reported to induce apoptosis through the mitochondrial pathway involving caspase 9 and Bax (18). Recently, Kohli et al (20) reported that Second mitochondrial-derived activator (Smac) plays an important role in NSAIDs-mediated apoptosis. Smac is an important pro-apoptotic component of the mitochondrial pathway of apoptosis $(21,22)$. Smac, in response to apoptotic signals, is released from mitochondria into cytosol and activates caspases by antagonizing the inhibitors of apoptosis (IAPs) (21-25). It remains unclear as to how Smac affects sulindac sulfide-mediated upregulation of DR5 and the downstream signaling events emanating from this death receptor. In this study, we have utilized Smac-proficient and deficient human colon cancer cells to investigate the role of Smac on sulindac sulfide-mediated DR5 regulation and the cross-talk between DR5dependent and mitochondrial pathways during sulindac sulfide-induced apoptosis.

\section{Materials and Methods}

\section{Materials, cell lines and cell culture}

Sulindac sulfide was provided by Merck (Rahway, NJ). McCoy's cell culture media, Penicillin/Streptomycin and L-Glutamine were purchased from Mediatech, Inc (Manassas, VA, USA). The fetal bovine serum was obtained from Gemini Bioproducts (Calabasas, CA, USA).
Smac-proficient and -deficient HCT116 human colon cancer cells (20) were used in this study and kindly provided by Dr. Bert Vogelstein (Johns Hopkins University, Baltimore, MD, USA). These cells were routinely cultured in McCoy's 5A medium (Mediatech, VA, USA) that was supplemented with $10 \%$ fetal bovine serum, 100 $\mathrm{U} / \mathrm{ml}$ Penicillin, $100 \mathrm{U} / \mathrm{ml}$ Streptomycin and $2 \mathrm{mM}$ L-Glutamine as also reported previously (27).

\section{Detection of apoptosis}

Smac-proficient or Smac-deficient cells were either not treated or treated with $130 \mu \mathrm{M}$ sulindac sulfide and approximately 24 hours later processed for apoptosis detection as reported previously (19, 27).

\section{Cytosolic fractions and Western blot analyses}

Smac-proficient or -deficient cells were not treated or treated with $130 \mu \mathrm{M}$ sulindac sulfide for approximately 24 hours and cytosolic fractions were prepared as described previously $(19,27)$.

Western blot analyses were performed as described (19) using a monoclonal anti-human DR5 antibody to detect DR5 (Oncogene Science, San Diego, CA, USA). Anti-human pro-caspase 3 (BD Bioscience, San Jose, CA, USA), anti-human procaspase 8 antibody and anti-human pro-caspase 9 antibody (Assay designs/Stressgene, Ann Arbor, MI, USA) were used to detect caspases 3, 8 and 9 activation. Bid cleavage was detected by using anti-Bid antibody purchased from R\&D, Minneapolis, MN, USA. A monoclonal anticytochrome c antibody from BD Bioscience (San Jose, CA, USA) was used to detect cytochrome c. A monoclonal anti-Smac antibody (Upstate Cell Signaling Solutions, Lake Placid, NY, USA) was used for the detection of Smac. Loading was determined by using $\beta$-actin monoclonal antibody purchased from Sigma Chemicals (St. Louis, MO, USA).

\section{Caspase enzymatic assay}

To detect caspase 3 activation, an enzymatic assay was performed as previously described (27). Briefly, $\mathrm{Smac}^{+/+}$or $\mathrm{Smac}^{-/}$deficient cells were treated with $130 \mu \mathrm{M}$ sulindac sulfide for 24 hours and cells were harvested and lysed in caspase 3 assay buffer. This buffer was composed of $50 \mathrm{mM}$ HEPES ( $\mathrm{pH}$ 7.4), ), $5 \mathrm{mM}$ CHAPs, $5 \mathrm{mM}$ dithiothreitol, and $10 \mathrm{mM}$ sodium pyrophosphate. After clarifying the lysates by centrifugation, $\sim 50$ $\mu \mathrm{g}$ of each cell lysate were mixed with $200 \mu \mathrm{l}$ 
of caspase assay buffer and $15 \mu \mathrm{M}$ caspase 3 fluorogenic substrate (Ac-DEVD-AMC, BD Pharmingen, San Jose, CA, USA) at room temperature for $\sim 60 \mathrm{~min}$ (27). To determine caspase3 activity, we used Synergy HT Microplate Reader (BIOTEK Instruments, Winoosski, VA, USA) with excitation at $380 \mathrm{~nm}$ and emission at $460 \mathrm{~nm}$.

\section{Northern blotting}

Extraction of total RNA and Northern blot analyses were done by standard procedures as described previously (28). A probe of human DR5 cDNA was used for detection of DR5 mRNA levels. Gels carrying RNA samples were stained with ethidium bromide to determine RNA integrity (28).

\section{Results and Discussion}

Smac-proficient $\left(\mathrm{Smac}^{+/+}\right)$and Smac-deficient $\left(\right.$ Smac $\left.^{-/}\right)$HCT116 human colon cancer cells were used in this study (20). Smac alleles have been deleted in Smac-deficient cells and as a consequence no Smac protein is expressed. We treated both Smac-deficient and -proficient cells with sulindac sulfide and as shown in Figure 1, Smac-deficient cells are less sensitive to undergo apoptosis in response to sulindac sulfide than the Smacproficient counterparts. Next, we investigated the effect of sulindac sulfide on cytosolic Smac levels and as shown in Figure 2, sulindac sulfide effectively increases cytosolic Smac levels in Smac-proficient cells and as expected, Smac-deficient cells do not exhibit Smac expression. These results therefore, suggest that Smac appears to be involved in the apoptotic signals engaged by sulindac sulfide.

Because sulindac sulfide has previously been reported to engage the intrinsic pathway of apoptosis (18), we also investigated the effect of Smac-deficiency on sulindac sulfide regulation of intrinsic pathway of apoptosis. Our results shown in Figure 3 indicate that sulindac sulfide-mediated apoptosis involves cytochrome c release from mitochondria into cytosol in Smac-proficient cells but in Smac-deficient cells, cytochrome c release into cytosol is reduced. Smac is known to activate caspases by antagonizing IAPs (21-26). Therefore, we also investigated sulindac sulfide effect on activation of caspases 9 and 3 in both cell types and our results shown in Figure 3, indicate that caspases 9 and 3 activations are also diminished in Smacdeficient cells when compared with Smac-proficient cells. Caspase 3 activation was further confirmed by enzymatic assay and the results were in line with those determined by Western blotting (Figure 4).

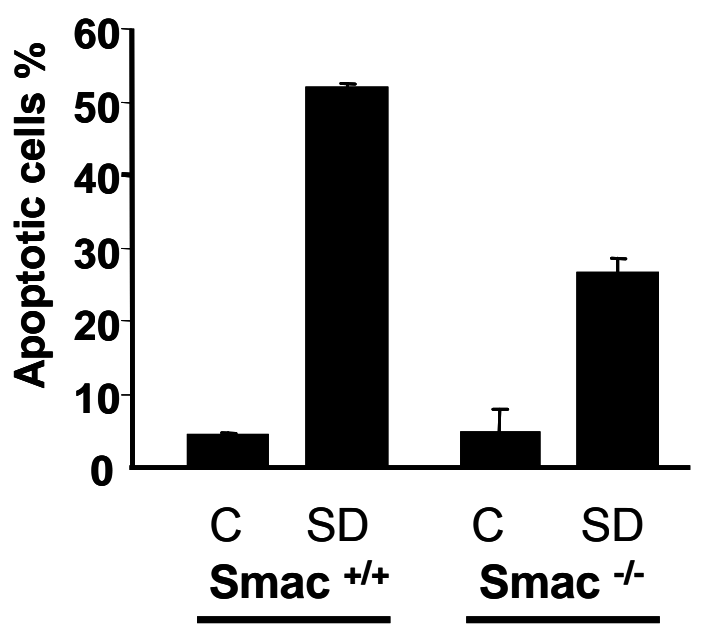

Figure 1. Apoptotic effects of sulindac sulfide in Smacproficient and -deficient cells. Smac-proficient $\left(\mathrm{Smac}^{+/+}\right)$or Smacdeficient $\left(\mathrm{Smac}^{-1-}\right)$ HCT116 human colon cancer cells were not treated or treated with sulindac sulfide (SD; $130 \mu \mathrm{M})$ for approximately 24 hours. Cell death was detected as described in Materials and Methods. The values are mean \pm s.e.m. of three independent experiments.

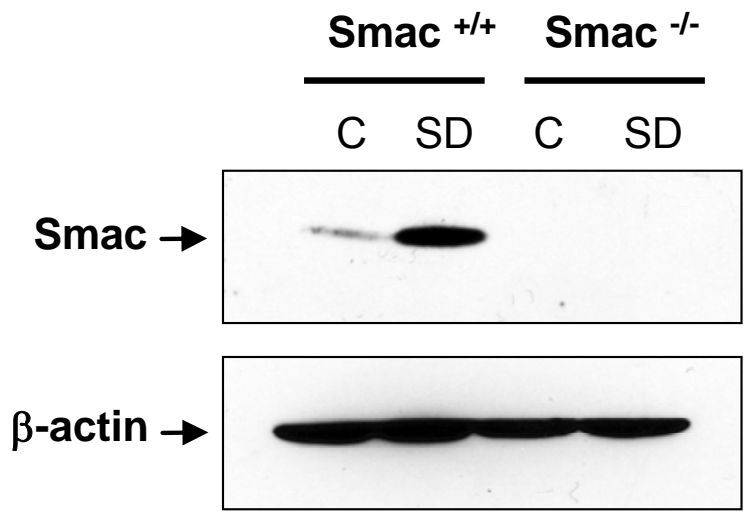

Figure 2. Sulindac sulfide effects on cytosolic Smac in Smacproficient and -deficient cells. Smac-proficient $\left(\mathrm{Smac}^{+/+}\right)$or Smacdeficient $\left(\mathrm{Smac}^{-1-}\right)$ cells were not treated or treated with $130 \mu \mathrm{M}$ sulindac sulfide for approximately 24 hours. Cytosolic fractions were prepared and the anti-Smac antibody was used to perform Western blotting. The same blots were also probed with anti- $\beta$-actin antibody to detect $\beta$-actin as a loading control.

Our previous results indicate that sulindac sulfidemediated apoptosis involves death receptor 5 upregulation and activation of caspase 8 (17). Caspase 8 is a proximal caspase that is directly engaged at the death inducing signaling complex (DISC) involving death receptors and other adaptor molecules (29). Sulindac sulfide is known to promote Bid cleavage to engage the intrinsic pathway of apoptosis (17). We therefore, sought to explore the effect of Smac deficiency on sulindac sulfide regulation of DR5, activation of caspase 8 and Bid 


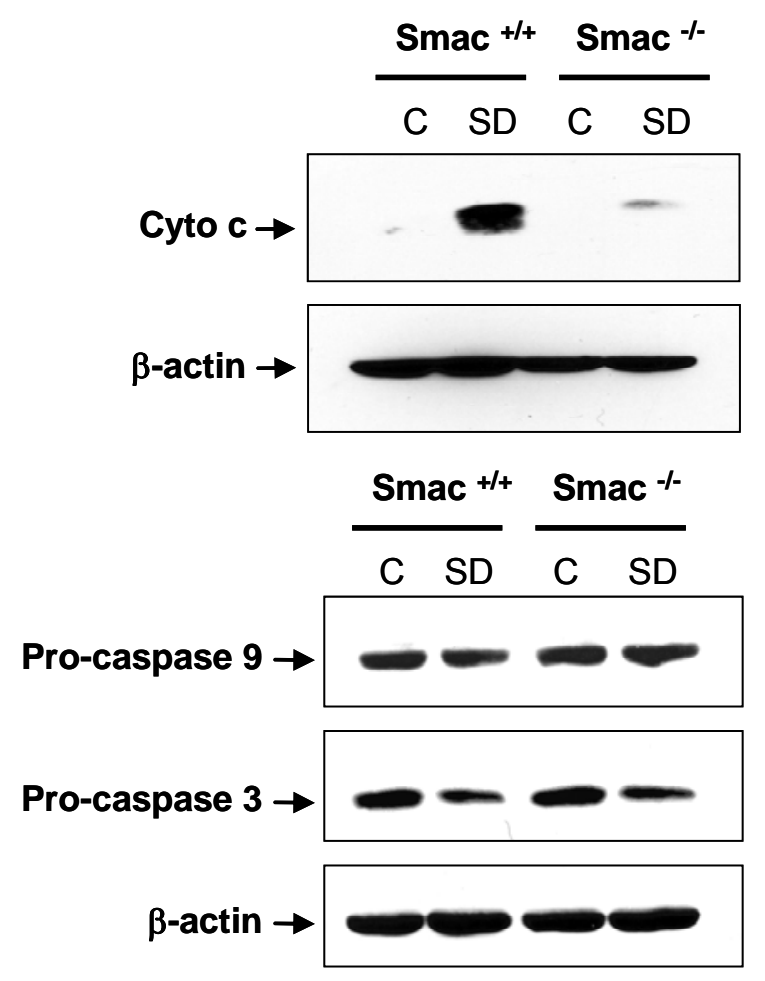

Figure 3. Sulindac sulfide effects on cytochrome $c$ and caspases in Smac-proficient and -deficient cells. Smac-proficient $\left(\mathrm{Smac}^{+/+}\right)$or Smac-deficient $\left(\mathrm{Smac}^{-1-}\right)$ cells were not treated or treated with $130 \mu \mathrm{M}$ sulindac sulfide for approximately 24 hours. Cytosolic fractions were prepared and Western blotting was done using the anti-cytochrome $c$ antibody. For loading controls, the same blots were also probed with the anti- $\beta$-actin antibody to detect $\beta$-actin. For caspase activations, cells were similarly treated with sulindac sulfide or left untreated, harvested and processed for Western blotting, the same blot was sequentially probed with the indicated antibodies including anti-caspases 9 and 3 , and $\beta$-actin.

cleavage. First, we investigated sulindac sulfide regulation of DR5 in both of these cell types and our results (Figure 5) indicate that sulindac sulfide upregulates DR5 expression at mRNA and protein levels in both Smac-proficient and-deficient cells. Next, we investigated sulindac sulfide effect on caspase 8 activation and Bid cleavage and our results (Figure 6) show that although sulindac sulfide is capable of inducing caspase 8 activation and Bid cleavage in Smac-proficient cells, these effects are blunted in Smac-deficient cells. We also noted that the constitutive levels of caspase 8 were decreased in the Smac-deficient cells, a finding which is consistent with our recently reported results (27).

In this manuscript, we report that Smac appears to be an important molecule in the signaling events engaged by sulindac sulfide to induce apoptosis, as sulindac sulfide-induced apoptosis is reduced in

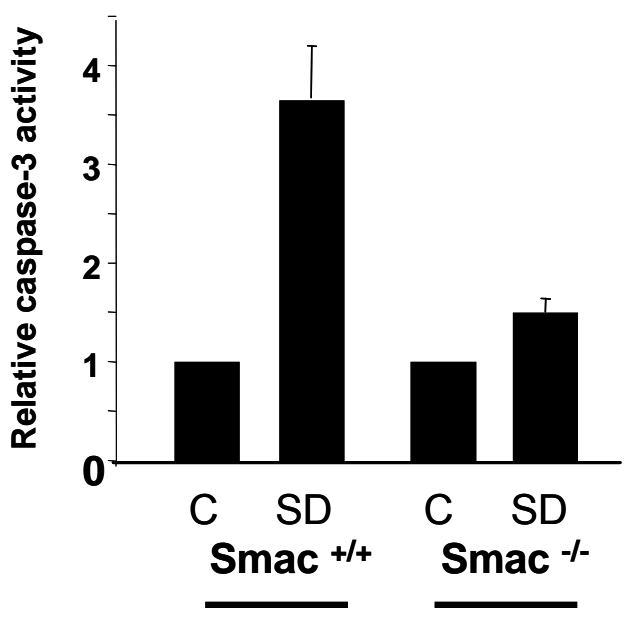

Figure 4. Caspase 3 activation induced by sulindac sulfide in Smac-proficient and -deficient cells. Smac -proficient $\left(\mathrm{Smac}^{+/+}\right)$or Smac-deficient $\left(\mathrm{Smac}^{-1-}\right)$ cells were not treated or treated with sulindac sulfide $(130 \mu \mathrm{M})$ for approximately 24 hours then harvested and prepared for caspase 3 enzymatic activity assay. The indicated values represent mean \pm s.e.m. of three independent experiments.

Smac-deficient cells when compared to Smacproficient counterparts. Our results indicate that sulindac sulfide-induced apoptosis involves engagement of DR5 and mitochondrial pathways in Smac-proficient cells. However, Smac deficiency, although not affecting sulindac sulfide to regulate DR5, alters its ability to activate caspase 8 and Bid cleavage suggesting that a cross-talk involving DR5 and the intrinsic pathway may be abrogated. Consistent with this concept, cytochrome c release from mitochondria into cytosol is diminished in sulindac sulfide-treated Smac-deficient cells. These results are therefore, consistent with those reported by Kohli et al (20) and our recent findings (27) that Smac deficiency also abrogates cytochrome c release into cytosol in response to thapsigargin-induced apoptosis--results that appear to place Smac upstream of cytochrome c. Smac is known to antagonize IAPs and thereby activate caspases. For example, Smac induces its pro-apoptotic effects via its interactions with IAP family proteins and consequently alleviating the IAP-mediated negative effects on caspases 3,7 , and 9 (21-26). Consistent with this notion, our results indicate that Smac deficiency also affects sulindac sulfide-mediated activation of caspases 3 and 9 .

Smac is a key component of the apoptotic signal transduction. Further in-depth studies as to how its regulation and function affect the flow of apoptotic signal will provide valuable information to further the progress in this area. Our results indicate that 


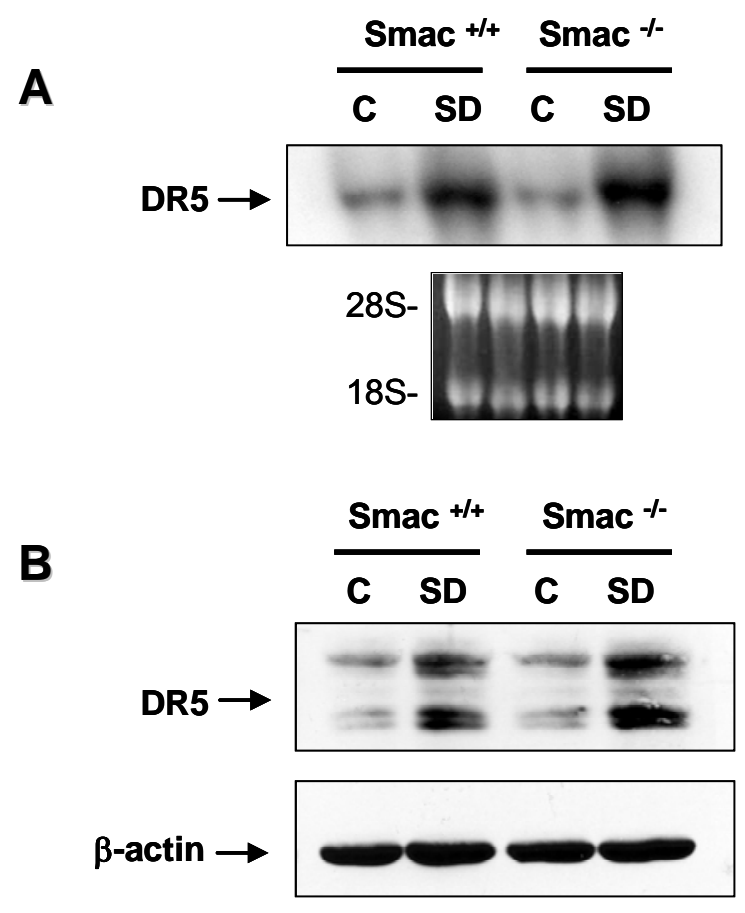

Figure 5. (A) Northern blot showing sulindac sulfide-mediated upregulation of death receptor 5 (DR5) mRNA levels in Smacproficient and -deficient cells. Smac -proficient $\left(\mathrm{Smac}^{+++}\right)$or Smacdeficient $\left(\mathrm{Smac}^{-1-}\right)$ cells were not treated or treated with sulindac sulfide $(130 \mu \mathrm{M})$ for approximately 24 hours. Cells were harvested and total RNAs were extracted and Northern analysis was performed as previously described $(17,19)$. A human DR5 cDNA was used as a probe; ethidium bromide staining of the gel shows RNA integrity. (B) Western blot showing sulindac sulfide-mediated upregulation of death receptor 5 (DR5) protein levels in Smac-proficient and deficient cells. Smac -proficient $\left(\mathrm{Smac}^{+/+}\right)$or Smac-deficient $(\mathrm{Smac}$ $\left.{ }^{1-}\right)$ cells were not treated or treated with sulindac sulfide $(130 \mu \mathrm{M})$ for approximately 24 hours. Cells were harvested and Western blot analysis was performed using the anti-DR5 antibody. Same blot was also probed with anti- $\beta$-actin antibody to ascertain comparable loading in each lane.

Smac plays a role in modulating the apoptotic signals mediated by sulindac sulfide, an important NSAID. Further investigation of the molecular mechanisms as to how Smac modulate sulindac sulfide and other NSAIDs-mediated apoptosis will also facilitate improvements in the utility of existing NSAIDs and development of newer ones.

\section{Acknowledgements}

Authors thank Dr. Bert Vogelstein for generously providing the Smac-proficient and -deficient HCT116 cells. This work was supported in part by NIH Grants ES016668, ES005633 (to MSS) and CA121850 (to YH).

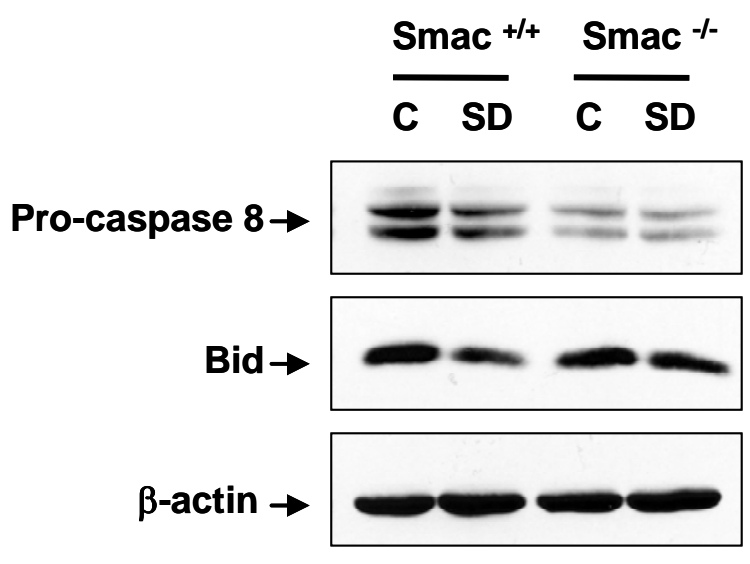

Figure 6. Sulindac sulfide effect on caspase 8 activation and Bid cleavage in Smac-proficient and -deficient cells. Smac -proficient $\left(\mathrm{Smac}^{+/+}\right)$or Smac-deficient $\left(\mathrm{Smac}^{-/-}\right)$cells were not treated or treated with sulindac sulfide $(130 \mu \mathrm{M})$ for approximately 24 hours then harvested and Western blotting was performed using anticaspase 8 or anti-Bid antibodies. Anti- $\beta$-actin antibody was used to probe the same blot to determine loading in each lane.

\section{References}

1. Williams CS, Mann M, DuBois RN. The role of cyclooxygenases in inflammation, cancer, and development. Oncogene 1999;18:7908-15.

2. Marnett LJ, DuBois RN. COX-2: a target for colon cancer prevention. Annu Rev Pharmacol Toxicol 2002;42:55-80.

3. Thun MJ, Namboodiri MM, Heath CJ Jr. Aspirin use and reduced risk of fatal colon cancer. N Engl J Med 1991;325:1593-6.

4. Schreinemachers DM, Everson RB. Aspirin use and lung, colon, and breast cancer incidence in a prospective study. Epidemiology 1994;5:138-46.

5. Smalley W, Ray WA, Daugherty J, Griffin MR. Use of nonsteroidal anti-inflammatory drugs and incidence of colorectal cancer. Arch Intern Med 1999;159:161-6.

6. Thun, MJ, Henley SJ, Patrono C. Nonsteroidal Antiinflammatory Drugs as Anticancer Agents: Mechanistic, Pharmacologic, and Clinical Issues. J Natl Cancer Inst 2002;94:252-66.

7. Grosser T, Fries S, FitzGerald GA. Biological basis for the cardiovascular consequences of COX-2 inhibition: therapeutic challenges and opportunities. J Clin Invest 2006;116: 4-15.

8. Boolbol SK, Dannenberg AJ, Chadburn A, Martucci C, Guo XJ, Ramonetti JT, et al. Cyclooxygenase-2 overexpression and tumor formation are blocked by sulindac in a murine model of familial adenomatous polyposis. Cancer Res 1996;56:2556-60.

9. Chiu CH, McEntee MF, Whelan J. Sulindac causes rapid regression of preexisting tumors in Min/+ mice independent of prostaglandin biosynthesis. Cancer Res 1997;57:4267-73. 
10. Labayle D, Fischer D, Vielh P, et al. Sulindac causes regression of rectal polyps in familial adenomatous polyposis. Gastroenterology 1991;101:635-9.

11. Giardiello FM, Hamilton SR, Krush AJ, et al. Treatment of colonic and rectal adenomas with sulindac in familial adenomatous polyposis. N Engl J Med 1993;328:1313-6.

12. Lynch HT, Thorson AG, Smyrk T. Rectal cancer after prolonged sulindac chemoprevention. A case report. Cancer 1995;75:936-8.

13. Tonelli F, Valanzano R. Sulindac in familial adenomatous polyposis [letter]. Lancet 1993;342:1120.

14. Lim JT, Piazza GA, Han EK, et al. Sulindac derivatives inhibit growth and induce apoptosis in human prostate cancer cell lines. Biochem. Pharmacol 58: 10971107, 1999.

15. Chan TA, Morin PJ, Vogelstein B, Kinzler KW. Mechanisms underlying nonsteroidal anti-inflammatory drug-mediated apoptosis. Proc Natl Acad Sci USA

1998;95:681-86.

16. Shiff SJ, Qiao L, Tsai L-L, Rigas B. Sulindac sulfide, an aspirin-like compound, inhibits proliferation, causes cell cycle quiescence, and induces apoptosis in HT-29 colon adenocarcinoma cells. J Clin Invest 1995;96:491-503.

17. Huang Y, He Q, Hillman MJ, Huang Y, Sheikh M.S. Sulindac Sulfide-induced Apoptosis Involves Death Receptor 5 and the Caspase 8-dependent Pathway in Human Colon and Prostate Cancer Cells. Cancer Res 2001;61:6918-24.

18. Zhang L, Yu J, Park BH, Kinzler K W, Vogelstein B. Role of BAX in the apoptotic response to anticancer agents. Science 2000;290:989-92.

19. He Q, Luo X, Huang Y and Sheikh MS. Apo2L/TRAIL differentially modulates the apoptotic effects of sulindac and a COX-2 selective non-steroidal anti-inflammatory agent in Bax-deficient cells. Oncogene 2002;21:6032-40.

20. Kohli M, Yu J, Seaman C, et al. SMAC/Diablodependent apoptosis induced by nonsteroidal antiinflammatory drugs (NSAIDs) in colon cancer cells. Proc Natl Acad Sci USA 2004;101:16897-902.

21. Du C, Fang M, Li Y, Wang X. Smac, a mitochondrial protein that promotes cytochrome c-dependent caspase activation by eliminating IAP inhibition. Cell 2000;102:33-42.

22. Verhagen AM, Ekert PG, Pakusch M, et al. Identification of DIABLO, a mammalian protein that promotes apoptosis by binding to and antagonizing IAP proteins. Cell 2000;102:43-53.

23. Chai J, Du C, Wu JW, Kyin S, Wang X, Shi Y. Structural and biochemical basis of apoptotic activation by Smac/DIABLO. Nature 2000;406:855-62.

24. Shiozaki EN, Shi Y. Caspases, IAPs and Smac/DIABLO: mechanisms from structural biology. Trends Biochem Sci 2004;29:486-94.

25. Wu G, Chai J, Suber TL, Wu JW, Du C, Wang X, Shi Y. Structural basis of IAP recognition by Smac/DIABLO. Nature 2000;408:1008-12.
26. Liu Z, Sun C, Olejniczak ET, et al. Structural basis for binding of Smac/DIABLO to the XIAP BIR3 domain. Nature 2000;408:1004-8.

27. He Q, Shi JX, Jones S, et al. Smac deficiency affects endoplasmic reticulum stress-induced apoptosis in human colon cancer cells. Mol Cell Pharmacol 2009;1:23-28.

28. He Q, Lee DI, Rong R, et al. Endoplasmic reticulum calcium pool depletion-induced apoptosis is coupled with activation of the death receptor 5 pathway. Oncogene 2002;21:2623-33.

29. Askkenazi A, Dixit VM. Apoptosis control by death and decoy receptors. Curr Opin Cell Biol 1999;11:255-60. 